\title{
Qualidade da auditoria no futebol e seus reflexos no valor das marcas dos clubes brasileiros*
}

\section{Calidad de la auditoría en el fútbol y sus reflejos en el valor de las marcas de los clubes brasileros Audit quality in soccer and its influence on the brand value of Brazilian clubs}

Ronan Reis Marçal

Universidade Federal de Santa Catarina, Brasil

m.ronanreis@gmail.com

ORCID: https://orcid.org/0000-0002-7922-2364

\section{Luiz Alberton}

Universidade Federal de Santa Catarina, Brasil

ORCID: https://orcid.org/0000-0001-9611-3859
DOI: https://doi.org/10.11144/Javeriana.cc22.qafr

Recepção: 16/11/2019

Aprovação: 22/04/2021

Publicação: 18/08/2021

\section{Resumo:}

Este estudo analisa a influência da qualidade da auditoria no valor das marcas dos clubes brasileiros de futebol. Para tal, foram realizadas regressões múltiplas com dados em painel diante de uma amostra de 20 diferentes clubes de futebol do Brasil entre 2014 e 2018. Os resultados indicam influência da qualidade da auditoria no valor das marcas dos clubes, sendo o tempo de permanência das firmas e o rodízio das firmas de auditoria fatores positivos nessa relação. Isto evidencia a relevância de uma auditoria de qualidade no âmbito do futebol, demarcado por práticas ruins de gestão. Em termos práticos, os resultados auxiliam stakeholders na avaliação do valor de mercado dos clubes, ao esclarecer aspectos dúbios para os torcedores, o que tem impacto na esfera social do esporte.

Códigos JEL: M42, Z23.

Palavras-chave: Futebol, auditoria, qualidade da auditoria, valor das marcas.

\section{Resumen:}

Este estudio analiza la influencia de la calidad de la auditoría en el valor de las marcas de los clubes de fútbol brasileños. Para esto, se realizaron regresiones múltiples con datos de panel frente a una muestra de 20 clubes de fútbol brasileños diferentes entre 2014 y 2018. Los resultados indican la influencia de la calidad de la auditoría en el valor de las marcas del club, siendo la duración de la estadía de las firmas y la rotación de las firmas de auditoría factores positivos en esta relación. Esto evidencia la relevancia de una auditoría de calidad en el campo del fútbol, marcado por malas prácticas de gestión. En términos prácticos, los resultados ayudan a las partes interesadas a evaluar el valor de mercado de los clubes, ya que aclaran aspectos dudosos para los fanáticos, lo que tiene impacto en la esfera social del deporte.

Códigos JEL: M42; Z23.

Palabras clave: Fútbol, auditoria, calidad de auditoría, valor de marca.

\section{Abstract:}

This study analyzes the influence of audit quality on the brand value of Brazilian football clubs. For this, multiple regressions with panel data were performed in front of a sample of 20 different Brazilian football clubs between 2014 and 2018. The results indicate the influence of the audit quality on the clubs' brand value. The tenure and the rotation of audit firms were positive factors in this relationship. That evidences the relevance of audit quality in the field of football, marked by bad management practices. In practical terms, the results help stakeholders in assessing the market value of clubs, as they clarify dubious aspects for fans, reaching the social sphere of the sport.

JEL Codes: M42, Z23.

Keywords: Football, audit, audit quality, brand value. 


\section{Introdução}

O futebol é o esporte mais popular do Brasil e, por tanto, uma grande quantia de recursos financeiros é movimentada anualmente nesse âmbito (Figueiredo, Santos \& Cunha, 2017; Silva, Santos \& Cunha, 2017). A mídia e parte da população, de uma forma geral, têm se atentado ao futebol não somente em sua vertente esportiva, mas também na financeira (Dantas \& Boente, 2011).

Neste sentido, os aspectos financeiros dos clubes de futebol são de grande interesse, dado que este esporte abarca elementos culturais que geram uma conexão afetiva do público com as entidades envolvidas, no caso, os clubes. (Holanda, Meneses, Mapurunga et al., 2012).

Rezende e Dalmácio (2015) afirmam que, mesmo sendo os torcedores os consumidores finais de toda e qualquer ação do futebol, as gestões dos clubes são majoritariamente amadoras, sendo destacadas por atos de ineficiência, corrupção e fraudes que, por sua vez, denotam um descrédito da imagem dos clubes perante a sociedade. No entanto, Silva e Carvalho (2009) alegam que, no Brasil, os grandes clubes, valendo-se de sua popularidade ante ao público, conseguem manter marcas muito fortes no mercado ainda que haja incertezas no que tange aos seus desempenhos financeiros e suas condutas de gestão por parte dos torcedores.

Condições similares de insegurança quanto às práticas de gestão e quanto ao conteúdo informacional contábil em si, em um ambiente sem as peculiaridades do futebol, como o mercado de capitais, gerariam reflexos negativos no valor de mercado das empresas. Isso foi comprovado, por exemplo, por Cox e Weirich (2002), quando atestaram empiricamente a reação negativa das ações de empresas do mercado dos Estados Unidos entre 1992 e 1999, antes e após o anúncio de eventos fraudulentos. Os autores concluíram também que os órgãos reguladores e as firmas de auditoria são fundamentais no processo de fiscalização das empresas.

Em relação à auditoria, DeAngelo (1981) define-a como de qualidade quando há percepção do mercado de que um determinado auditor consiga detectar e reportar alguma infração contábil, caso ela de fato exista.

Defond e Zhang (2014), por sua vez, entendem que os benefícios de uma auditoria de alta qualidade são superiores ao mero julgamento das demonstrações contábeis em um caráter binário de "certo" ou "errado". Os autores esclarecem que a qualidade da auditoria tende a gerar confiabilidade para os usuários externos quanto às informações contábeis reportadas pelas entidades. Estudos como os de Teoh e Wong (1993) e Ghosh e Moon (2005) reportam evidências empíricas de que serviços de auditoria de alta qualidade retornam reaçóes positivas do mercado.

Por se tratar de entidades sem fins lucrativos, os clubes de futebol não possuem um valor de mercado definido. A empresa BDO RCS Auditores Independentes, desde 2008, realiza um estudo anual que visa mensurar o valor das marcas dos clubes de futebol do Brasil em função de informações financeiras, de marketing, de perfil de consumo dos torcedores, entre outras. A métrica foi desenvolvida com o intuito de contribuir com o mercado do futebol no âmbito dos negócios (BDO, 2018), sendo utilizada, por exemplo, na recente pesquisa de Marçal (2018).

Destarte, considerando (I) o apelo público e midiático em torno dos clubes de futebol do Brasil; (II) a gestão precária percebida em tais entidades; (III) os reflexos positivos gerados pela qualidade da auditoria prestada em instituições com propósitos de lucro; e (IV) a disponibilização de uma medida equivalente ao valor de mercado para os clubes de futebol do Brasil, este trabalho teve como objetivo analisar a influência da qualidade da auditoria no valor das marcas dos clubes brasileiros de futebol.

Justifica-se tal objetivo diante da importância das informações contábeis para os sócios-torcedores no processo de avaliação do desempenho econômico-financeiro dos clubes de futebol (Moreira, Firmino, Silva \& Silva, 2013) e da maior confiança nos reportes das demonstrações contábeis devidamente auditadas (Kaveski \& Cunha, 2016), em especial quando há evidências de qualidade da auditoria (Defond \& Zhang, 2014). Estes fatos, associados aos rotineiros hábitos de má gestão em clubes de futebol (Rezende \& Dalmácio, 2015; Oliveira, Borba, Ferreira \& Lunkes, 2017), sugerem que a auditoria de qualidade pode ser ainda mais relevante na determinação do valor de mercado em se tratando de clubes de futebol. 
Ademais, de acordo com Silva, Moreira, Firmino et al. (2016) e Silva et al. (2017), há uma lacuna no que se refere ao estudo dos efeitos da auditoria independente nos clubes de futebol. Assim, o presente trabalho contribui teoricamente ao agregar resultados em um campo de pesquisas ainda escasso. Outrossim, são esperadas também contribuições práticas ao demonstrar a influência da auditoria de qualidade no cerne futebolístico em termos de avaliação das marcas dos clubes, algo relevante para os sócios, os torcedores, os dirigentes dos clubes e os demais stakeholders. Não menos importante, os resultados podem, ainda, contribuir em aspectos sociais dado o vínculo emocional criado pelos torcedores em relação aos seus clubes (Holanda et al., 2012).

\section{Referencial teórico}

\section{Aspectos legais e características da gestão do futebol no Brasil}

De acordo com Figueiredo et al. (2017), tanto a forma jurídica dos clubes brasileiros de futebol como o reconhecimento, a mensuração e a divulgação de seus fatos contábeis enfrentaram diversas modificações mediante as alterações feitas na legislação desportiva desde o século passado.

O primeiro normativo desse contexto é o Decreto-Lei n 3.199 de 1941, que proibia o propósito de lucro por parte de entidades desportivas, cabendo ao Estado regular todas as práticas desse âmbito.

Somente em 1993, conforme Umbelino, Silva, Ponte e Lima (2019), viria a ocorrer uma grande alteração nesse cenário por meio da Lei $\mathrm{n}^{\circ}$ 8.672, conhecida como Lei Zico. Os referidos autores relatam que este dispositivo trouxe aos clubes maior autonomia frente ao Estado, possibilitou a mudança das entidades desportivas para a condição de associações comerciais e concedeu aos clubes o chamado "passe" dos atletas. Todas essas medidas foram tomadas visando equipar a legislação vigente no Brasil aos estatutos internacionais e agregar mais recursos oriundos da iniciativa privada aos clubes.

A outorga do direito ao "passe" dos jogadores para os clubes foi algo inovador, contudo, relativamente controverso. Ocorre que, nessa modalidade, os jogadores eram equiparáveis a mercadorias, representando, assim, um vínculo em moldes medievais (Galindo, 2016).

Em 1998, surge a Lei n ${ }^{\circ} 9.615$ (Lei Pelé), que tem como uma das principais mudanças a extinção do "passe”, segundo Figueiredo et al. (2017). A partir desta publicação, o "passe" foi substituído pelos chamados "direitos federativos" que, na prática, se diferenciam do primeiro em função do aspecto de temporariedade definida mediante o prazo de vigência do contrato, além de permitirem a rescisão unilateral por ambas as partes do contrato dado o pagamento de multa pecuniária previamente acordada (Lopes \& Davis, 2007).

Além da redução das receitas dos clubes em função da extinção do "passe", a Lei Pelé viria a se tornar um transtorno para os dirigentes, dada a nova exigência de que os clubes deveriam se tornar empresas, algo prejudicial para as tradicionais práticas indevidas de gestão no futebol brasileiro (Silva \& Carvalho, 2009).

Este modelo, que poderia ser saudável na prevenção dos corriqueiros atos fraudulentos por gestores no meio futebolístico do país, funcionou pouco tempo como obrigatório, sendo tratado como de caráter opcional com o advento da Lei $n^{\circ} 10.672$ de 2003 . Não obstante, a manutenção do status de entidades sem fins lucrativos gera aos clubes a imunidade tributária sobre a renda e o patrimônio (Rezende \& Dalmácio, 2015), assim, era de se esperar que os clubes, em massa, não aderissem a proposta de mudança para o formato de clubesempresas (Mattar, 2014).

Somente com a adoção da Lei $\mathrm{n}^{\circ} 10.672$ os clubes brasileiros de futebol, independentemente da forma jurídica adotada, tornaram-se obrigados a divulgar suas demonstrações contábeis no padrão das Sociedades Anônimas (S.A.), incluindo a exigência de auditoria independente para estas publicações. Todo isto, pese ao fato de que a análise das demonstrações contábeis seja uma importante ferramenta para a avaliação das empresas, sejam elas com ou sem fins lucrativos (Silva \& Carvalho, 2009). 


\section{Qualidade da auditoria}

De acordo com Dantas e Medeiros (2015), embora o tema "qualidade da auditoria" seja amplamente difundido na literatura internacional desde DeAngelo (1981), em âmbito nacional, as pesquisas só começaram a surgir a partir da primeira década dos anos 2000. Além disso, frisam os autores que conquanto uma auditoria de qualidade seja elemento fundamental para a determinação de confiança e credibilidade nos mercados, dúvidas como "o que é uma auditoria de qualidade?" e "como mensurar uma auditoria de qualidade?" são habituais.

O primeiro questionamento é tradicionalmente explanado como o entendimento do mercado, de uma forma geral, de que um deliberado auditor seja apto a identificar e reportar algum descumprimento de ordem contábil quando esse venha a existir (DeAngelo, 1981). Embora este seja o conceito clássico, vale ressaltar o exposto de Defond e Zhang (2014) de que uma auditoria de qualidade adentra outros benefícios, a exemplo da oferta de maior credibilidade aos usuários externos quanto ao conteúdo informacional reportado, não se limitando a fixar um rótulo de certo ou errado para as demonstrações contábeis.

Já em relação ao segundo questionamento, Khani e Noroozian (2018) explicam que, por se tratar de algo não observável ex ante, a qualidade da auditoria pode ser complexa em termos de sua mensuração. Como forma de superar este entrave, algumas medidas oriundas dos relatórios de auditoria são recorrentemente utilizadas como proxies de qualidade. Por exemplo, o tamanho da firma de auditoria, o tempo de permanência de uma firma de auditoria na relação com um dado cliente e o rodízio das firmas de auditoria (Defond \& Zhang, 2014).

O tamanho das firmas de auditoria é, talvez, a proxy mais tradicional nas pesquisas sobre a qualidade da auditoria. Isso é sugerido desde o seminal trabalho de DeAngelo (1981). A autora em questão explica que o tamanho da firma está diretamente ligado ao conceito de qualidade da auditoria, porque uma firma com muitos clientes tem "mais a perder" ao não perceber uma infração nas demonstrações contábeis de seus clientes. Nessa esteira seguiram os resultados de Becker, DeFond, Jiambalvo e Subramanyam (1998); Deis Jr. e Giroux (1992); Teoh e Wong (1993) e Silvestre, Costa e Kronbauer (2018).

No que concerne ao tempo de permanência das firmas de auditoria em um relacionamento com um cliente específico, Manry, Mock e Turner (2008) relatam que um corpo substancial de pesquisas acadêmicas trata como prejudicial o relacionamento de curto prazo entre o cliente e a firma de auditoria. São exemplos os estudos de Myers, Myers e Omer (2003) e Ghosh e Moon (2005), que apontam o relacionamento de longo prazo entre a firma de auditoria e o cliente como fator positivo para a melhoria na qualidade dos lucros por meio da redução dos accruals discricionários e do coeficiente de resposta ao lucro, respectivamente.

Contudo, cabe destacar que este tema apresenta algumas inconsistências de resultados, segundo Junaidi, Apriyanto, Nurdiono e Suwardi (2014). Os autores explicam que o longo relacionamento entre auditores e auditados também pode vir a afetar negativamente o nível de independência dos auditores, reduzindo a qualidade dos trabalhos (Carey e Simnett, 2006; Al-Thuneibat, Al Isa \& Ata Baker, 2011). Embora os resultados de sua pesquisa não evidenciem qualquer relação estatisticamente significativa entre o tempo de permanência e a qualidade da auditoria, Junaidi et al. (2014) indicam a continuidade de pesquisas nesse sentido utilizando outras amostras para melhor elucidar essa questão.

Similar ao contexto de resultados sobre o período de permanência, o rodízio das firmas também apresenta resultados ambíguos na literatura quanto ao quesito qualidade da auditoria.

Autores como Beck e Wu (2006) argumentam que o rodízio prejudica a qualidade da auditoria, devido a que todo o conhecimento específico adquirido pela firma de auditoria sobre as atividades de seu cliente durante seu relacionamento será preterido diante do início da relação do cliente com uma nova firma de auditoria.

Contudo, Defond e Zhang (2014) afirmam que a maioria dos estudos sobre a qualidade da auditoria trata o rodízio como algo benéfico, dado que há um aumento da independência do auditor, dada a inexistência 
de laços anteriores com o novo cliente. Isso foi confirmado por Defond e Subramanyam (1998) quando perceberam redução nas práticas de gerenciamento de resultados via accruals discricionários diante da troca das firmas de auditoria no mercado dos Estados Unidos da América. O mesmo resultado foi encontrado na recente pesquisa nacional realizada por Silvestre et al. (2018).

\section{Estudos anteriores}

Estudos como os de Dantas e Boente (2011), Silva et al. (2016) e Figueiredo et al. (2017) destacam que as pesquisas acerca do futebol tenham se tornado frequentes na literatura acadêmica contábil. Entretanto, devese ressaltar que, no que se refere ao estudo acerca da auditoria independente neste cerne, as pesquisas ainda são escassas (Silva et al., 2016; Silva et al., 2017). Nessa aparente lacuna literária, destacam-se os resultados de alguns trabalhos apresentados a seguir.

Silva e Carvalho (2009) buscam saber se existe alguma relação entre a transparência e o desempenho dos clubes da série A do Brasil. Os autores utilizam o parecer dos auditores como uma das métricas para a criação de seu índice de mensuração de divulgação das informações contábeis, partindo da premissa de que este elemento é capaz de gerar mais credibilidade aos dados reportados aos usuários externos. Os resultados indicam que os clubes com melhor desempenho financeiro e esportivo são também os que melhor evidenciam suas demonstrações contábeis.

Rezende e Dalmácio (2015) fazem uma crítica à classificação dos clubes brasileiros como entidades sem fins lucrativos com base em evidências empíricas oriundas das demonstrações contábeis de 27 clubes das séries A, B e C. O estudo é sustentado pela Teoria da Agência (Jensen \& Meckling, 1976) sob a perspectiva de que mecanismos de governança corporativa - sendo a auditoria independente um de seus artefatos - reduziriam a assimetria informacional e inibiriam os possíveis conflitos de interesses dentro dos clubes. Os resultados da pesquisa sugerem que quanto maior for o nível de governança corporativa do clube, melhores serão seus respectivos resultados econômicos e esportivos.

Silva et al. (2016), considerando os dados de 24 clubes de futebol do Brasil entre 2010 e 2011, expóem que, no geral, a auditoria externa prestada no cenário futebolístico nacional é precária em termos de qualidade, propiciando riscos ao poder de crítica dos usuários, e favorecendo potenciais interessados na omissão de informações relevantes. Os autores focaram-se diretamente na qualidade da auditoria, utilizando como critério técnico a obrigatoriedade de divulgação do ativo intangível. Destaca-se também que, nessa pesquisa, somente um clube (Santos Futebol Clube) havia sido auditado por uma das Bigfour, evidenciando um cenário atípico quanto à concentração das firmas de auditoria.

Por sua vez, Silva et al. (2017) verificam e não rejeitam a hipótese de que o desempenho econômicofinanceiro esteja relacionado com o tipo de relatório de auditoria percebido pelos clubes. No geral, os resultados indicam que clubes mais endividados e com menor liquidez têm maior probabilidade de serem classificados com alguma ressalva nos relatórios de auditoria.

Já Figueiredo et al. (2017) visam identificar o nível de evidenciação contábil compulsória e voluntária dos clubes das séries A e B entre 2011 e 2015. Os autores percebem que a maioria dos clubes divulga as demonstrações obrigatórias por lei. Contudo, grande parte dessas publicações é acompanhada de pareceres de auditoria com ressalva quanto à inobservância de algum item, fato que compromete a qualidade da informação reportada pelos clubes, bem como deteriora a comparabilidade frente aos seus equivalentes. 


\section{Desenvolvimento das hipóteses de pesquisa}

Como visto os clubes brasileiros de futebol, em geral, se mantiveram como sociedades sem fins lucrativos (Mattar, 2014), refutando a possibilidade de mudança para a forma de clubes-empresas dada a manutenção de benefícios tributários e a menor exposição frente ao mercado.

Esta motivação parece estar alinhada ao relato de Rezende e Dalmácio (2015) de que as práticas de gestão no âmbito do futebol são caracterizadas por atos de corrupção, lavagem de dinheiro, dentre outros delitos ou, ao menos, por condutas ineficientes (Oliveira et al., 2017).

Nesse cenário, uma auditoria de qualidade seria capaz de gerar maior credibilidade às informações contábeis divulgadas pelos clubes, tal qual ocorrido em empresas de capital aberto (Defond \& Zhang, 2014). Essa lógica está de acordo com Silva e Carvalho (2009) quando dizem que, independentemente do propósito de lucro, as entidades podem ser bem avaliadas mediante a análise de suas demonstrações contábeis. Não obstante, Moreira et al. (2013) destacam a pertinência das demonstrações contábeis em termos de avaliação de desempenho econômico-financeiro em se tratando especificamente dos clubes de futebol.

Dadas a disponibilização de uma medida de valor de mercado - no caso, as marcas - para os clubes de futebol do Brasil (BDO, 2018), e a observação de que, mesmo diante das dúvidas do público em relação às práticas de gestão no futebol, os clubes conseguem manter marcas fortes (Carvalho \& Silva, 2009), foram elaboradas as seguintes hipóteses de pesquisa:

H1: O tempo de permanência das firmas de auditoria influencia o valor da marca dos clubes brasileiros de futebol.

H2: O rodízio das firmas de auditoria influencia o valor da marca dos clubes brasileiros de futebol.

A H1 é sustentada diante dos reflexos gerados pelo tempo de permanência da firma de auditoria em empresas com propósito de lucro, sejam esses reflexos em sentido positivo (Myers et al., 2003; Ghosh \& Moon, 2005), sejam eles em sentido negativo (Carey \& Simnett, 2006; Al-Thuneitbat et al., 2011).

De forma análoga, a $\mathrm{H} 2$ possui alicerce em resultados de pesquisas anteriores que evidenciaram melhorias em métricas diversas nas empresas em função do rodízio das firmas (Defond, \& Subramanyam, 1998; Silvestre et al., 2018), bem como coexistem indícios de que o rodízio prejudica as firmas de alguma forma (Beck \& Wu, 2006).

Um destaque a ser feito é que nenhum dos 20 clubes observados, durante o intervalo cronológico proposto para a seleção amostral, foi auditado por uma das Bigfour. A nuance de que os clubes brasileiros de futebol não são auditados por firmas de grande porte havia sido percebida por Silva et al. (2016), embora este estudo tenha identificado uma exceção.

Em relação a uma possível hipótese sobre o tamanho da firma de auditoria, deve-se dizer que este aspecto está diretamente atrelado à qualidade da auditoria em si (DeAngelo, 1981). Dado que a proxy do tamanho de firma de auditoria mais usual é justamente ser ou não ser uma firma entre as Bigfour, e que a qualidade dos serviços prestados pelas quatro maiores firmas de auditoria do mundo são superiores às demais firmas (Lawrence, Minutti-Meza \& Zhang, 2011), não foi possível verificar uma hipótese sobre este aspecto, limitando o estudo em função da relevância dessa variável para a mensuração da qualidade da auditoria (Defond \& Zhang, 2014).

\section{Metodologia}

A amostra é do tipo não-probabilística dado que foram selecionados vinte clubes de futebol do Brasil considerando o critério das vinte maiores marcas, em termos de valor, conforme pesquisa realizada pela BDO RCS Auditores Independentes (BDO, 2018). Tal pesquisa está em sua décima primeira versão e mensura o Valor das Marcas (VM) dos clubes diante de dados financeiros dessas entidades e de fatores como o perfil 
de consumo dos torcedores, marketing esportivo do clube, entre outros. Destaca-se, ainda, que o estudo realizado por Marçal (2018) também utilizou informações provenientes de tal pesquisa, porém, em sua edição de número 9.

Destarte, os clubes que compuseram a amostra são apresentados na tabela 1.

TABELA 1

Vinte maiores marcas de clubes de futebol do Brasil (em ordem alfabética)

\begin{tabular}{|l|c|c|}
\hline \multicolumn{1}{|c|}{ Nome } & Estado & Região \\
\hline Associação Atlética Ponte Preta & SP & Sudeste \\
\hline Associação Chapecoense de Futebol & SC & Sul \\
\hline Botafogo de Futebol e Regatas & RJ & Sudeste \\
\hline Club Athletico Paranaense & PR & Sul \\
\hline Club de Regatas Vasco da Gama & RJ & Sudeste \\
\hline Clube Atlético Mineiro & MG & Sudeste \\
\hline Clube de Regatas do Flamengo & RJ & Sudeste \\
\hline Coritiba Foot Ball Club & PR & Sul \\
\hline Cruzeiro Esporte Clube & MG & Sudeste \\
\hline Esporte Club Bahia & BA & Nordeste \\
\hline Esporte Clube Vitória & BA & Nordeste \\
\hline Fluminense Football Club & RJ & Sudeste \\
\hline Goiás Esporte Clube & GO & Centro-Oeste \\
\hline Grêmio de Foot-Ball Porto Alegrense & RS & Sul \\
\hline Internacional Sport Club & RS & Sul \\
\hline Santos Futebol Clube & SP & Sudeste \\
\hline São Paulo Futebol Clube & SP & Sudeste \\
\hline Sociedade Esportiva Palmeiras & SP & Sudeste \\
\hline Sport Club Corinthians Paulista & SP & Sudeste \\
\hline Sport Club do Recife & PE & Nordeste \\
\hline
\end{tabular}

Fonte: dados da pesquisa.

Foram coletados dados anuais - no intervalo que vai de 2014 a 2018 - que remetem ao tempo de permanência das firmas de auditoria externa como prestadoras de serviços dos clubes observados e ao momento da troca da firma de auditoria, ou seja, o rodízio. Tais informações foram verificadas diante das demonstrações contábeis dos clubes divulgadas em seus respectivos websites ou, em sua ausência, nas páginas eletrônicas das Federações Estaduais de Futebol ao qual estes clubes estão vinculados. Não houve ausência de dados para nenhuma unidade identificadora durante o processo de coleta, portanto, a priori, havia um painel de dados plenamente balanceado, viabilizando o acompanhamento cronológico dos clubes (Gujarati \& Porter, 2011).

Todavia, durante o tratamento dos dados, foi diagnosticada a ausência de normalidade dos resíduos da regressão proposta, descrita posteriormente nessa seção. Para mitigar o referido problema no intuito de assegurar que os intervalos de confiança fossem válidos, a variável VM foi transformada em sua forma logarítmica neperiana, gerando a variável lnVM. Além disso, foram eliminadas duas observações (ambas relacionadas com a Associação Chapecoense de Futebol), que apresentavam comportamentos extremos (outliers). Ambos os procedimentos estão de acordo com Fávero e Belfiore (2017) e são pormenorizados durante a seção de análise dos resultados.

Assim, a amostra que continha inicialmente 100 observações derivadas de 20 diferentes clubes, foi reduzida a 98 observações, sendo o conjunto de dados representado, portanto, por um painel desbalanceado (nem todas as unidades identificadoras apresentam dados em todos os períodos) e curto (há mais unidades identificadoras que períodos analisados).

Diante do interesse na variabilidade entre as unidades identificadoras, a abordagem de efeitos aleatórios fez-se mais pertinente para este estudo, sendo realizada, portanto, a estimação via Generalized Least Squares (GLS). A escolha da abordagem de efeitos aleatórios foi corroborada diante de testes estatísticos específicos, sugeridos como adequados para tal função por Fávero e Belfiore (2017) desde a consideração da amostra innicial até o momento da composição da amostral final. Os resultados de tais testes são apresentados na tabela 
TABELA 2

Escolha da abordagem dos dados em painel

\begin{tabular}{|c|c|c|}
\hline Momento & Teste & p-valor \\
\hline \multirow{3}{*}{$\begin{array}{l}\text { 1) Amostra inicial com } 100 \\
\text { observações e variável VM } \\
\text { em seu valor original }\end{array}$} & Chow & 0,0000 \\
\hline & $\begin{array}{l}\text { Multiplicador de Lagrange de } \\
\text { Breusch-Pagan }\end{array}$ & 0,0000 \\
\hline & Hausman & 0,5672 \\
\hline \multirow{3}{*}{$\begin{array}{l}\text { 2) Amostra inicial com } 100 \\
\text { observações e variável VM } \\
\text { em sua forma logarítmica } \\
\text { neperiana }\end{array}$} & Chow & 0,0000 \\
\hline & $\begin{array}{l}\text { Multiplicador de Lagrange de } \\
\text { Breusch-Pagan }\end{array}$ & 0,0000 \\
\hline & Hausman & 0,8618 \\
\hline \multirow{3}{*}{$\begin{array}{l}\text { 3) Amostra final com } 98 \\
\text { observações e variável VM } \\
\text { em sua forma logarítmica } \\
\text { neperiana }\end{array}$} & Chow & 0,0000 \\
\hline & $\begin{array}{l}\text { Multiplicador de Lagrange de } \\
\text { Breusch-Pagan }\end{array}$ & 0,0000 \\
\hline & Hausman & 0,9258 \\
\hline
\end{tabular}

Fonte: dados da pesquisa.

Dessa forma, a equação responsável por fornecer embasamento na verificação da hipótese geral de pesquisa foi o modelo 1 .

$$
\operatorname{lnVM} M_{i, t}=\beta_{0}+\beta_{1} N O R D_{i}+\beta_{2} S U D_{i}+\beta_{3} S U L_{i}+\beta_{4} \operatorname{LIBERT}_{i, t}+\beta_{5} P E R M_{i, t}+\beta_{6} R O D_{i, t}+\mu_{i, t}+\varepsilon_{i, t}
$$

Onde:

$\operatorname{lnVM} M_{i, t}$ é o logaritmo neperiano do Valor da Marca do clube $i$, no período $t$

$N O R D_{i, t}$ é uma variável dummy que assume valor 1 caso o clube $i$ pertença à região Nordeste

$S U D_{i, t}$ é uma variável dummy que assume valor 1 caso o clube $i$ pertença à região Sudeste

$S U L_{i, t}$ é uma variável dummy que assume valor 1 caso o clube $i$ pertença à região Sudeste

$\operatorname{LIBERT}_{i, t}$ é uma variável dummy que assume valor 1 caso o clube $i$ tenha participado da Copa

Libertadores no período $t$

$P E R M_{i, t}$ é o tempo de Permanência, em anos, de uma firma de auditoria x na prestação de serviços

ao clube $i$, no período $t$

$R O D_{i, t}$ é uma variável dummy que assume valor 1 caso tenha ocorrido o rodízio de firmas de

auditoria no clube $i$, no período $t$

$\beta_{0}$ é o intercepto da regressão

$\beta_{1,2,3, n}$ são os coeficientes angulares da regressão

$\mu_{i, t}$ é o termo de erro da variação entre os clubes $i$, no período $t$

$\varepsilon_{i, t}$ é o termo de erro da variação geral entre as observações dos clubes $i$, no período $t$

As variáveis NORD, SUD e SUL foram adicionadas como variáveis de controle após terem sido realizados testes de diferença de médias na variável lnVM (estes, reportados na seção seguinte), que identificaram discrepâncias entre todas as regiões demográficas dos clubes. A região Centro-Oeste foi escolhida como a categoria de referência.

A variável LIBERT, por sua vez, foi utilizada como variável de controle diante do resultado da pesquisa de Dantas et al. (2016), que verificaram uma maior eficiência na gestão dos custos operacionais quando os clubes estavam participando da Copa Libertadores, que é a principal competição de futebol da América do Sul. Assim, por se tratar de uma melhoria de caráter financeiro, esta variável poderia vir a ser relevante na especificação do modelo.

Todos os testes foram realizados com o auxílio do software STATA considerando sempre um nível de confiança de $95 \%$. 


\section{Análise dos resultados}

Em primeira instância, têm-se os resultados das estatísticas descritivas dos dados de pesquisa, conforme tabela 3.

TABELA 3

Estatísticas descritivas

\begin{tabular}{|c|c|c|c|c|c|}
\hline \multicolumn{6}{|c|}{ Painel A - Variáveis quantitativas } \\
\hline & Média & Mediana & Desvio-Padrão & Mínimo & Máximo \\
\hline VM & 460216326.53 & 349200000 & 456375536.65 & 23900000 & 1952100000 \\
\hline $\operatorname{lnVM}$ & 8,427934 & 8,542948 & 0,4899366 & 7,378398 & 9,290502 \\
\hline PERM & 3,44898 & 3 & 2,261841 & 1 & 10 \\
\hline \multicolumn{6}{|c|}{ Painel B - Variáveis binárias } \\
\hline & \multicolumn{3}{|c|}{$\mathrm{N}^{\circ}$ de casos " 0 " } & \multicolumn{2}{|c|}{$\mathrm{N}^{0}$ de casos " 1 " } \\
\hline LIBERT & \multicolumn{3}{|c|}{67} & \multicolumn{2}{|c|}{31} \\
\hline ROD & \multicolumn{3}{|c|}{76} & \multicolumn{2}{|c|}{22} \\
\hline NORD & \multicolumn{3}{|c|}{83} & \multicolumn{2}{|c|}{15} \\
\hline SUD & \multicolumn{3}{|c|}{43} & \multicolumn{2}{|c|}{55} \\
\hline SUL & \multicolumn{3}{|c|}{75} & \multicolumn{2}{|c|}{23} \\
\hline
\end{tabular}

Fonte: dados da pesquisa.

Os resultados indicam que a transformação da variável VM para sua forma logarítmica neperiana foi válida no sentido de mitigar a dispersão dos dados, uma vez que o desvio-padrão foi drasticamente reduzido. Isso, em conjunto com a proximidade entre a média e a mediana da variável $\operatorname{lnVM}$, indicam pouca influência de outliers.

Já em relação às variáveis dummies, fica perceptível a predominância da região Sudeste no conjunto amostral. Como o estudo de Marçal (2018) havia identificado uma diferença na média do valor das marcas quando os clubes dessa região estavam envolvidos em comparações, foram realizados testes de diferença de médias, de maneira similar, na presente pesquisa.

Segundo Razali e Wah (2011), em amostras pequenas, os testes de normalidade, de uma forma geral, não são confiáveis, podendo gerar resultados equivocados na pesquisa. Nessa esteira, e considerando que a normalidade dos dados é uma premissa para a adequada realização de testes paramétricos (Fávero \& Belfiore, 2017), foi feita uma interpretação gráfica do comportamento da variável VM em função dos subgrupos regionais.

Pelos gráficos reportados na figura 1 há sugestão de ausência de normalidade dos dados em todas as regiões. Assim, foi necessário realizar um teste não paramétrico de diferença de médias (Fávero \& Belfiore, 2017). Por se tratar de 4 subgrupos, o teste em questão é o de Kruskal Wallis. Todavia, este teste somente identifica se há diferença entre as médias por parte de ao menos um componente dentre os observados, não reportando as diferenças entre os pares. Para esta segunda função, foram realizados testes de Mann-Whitney. 

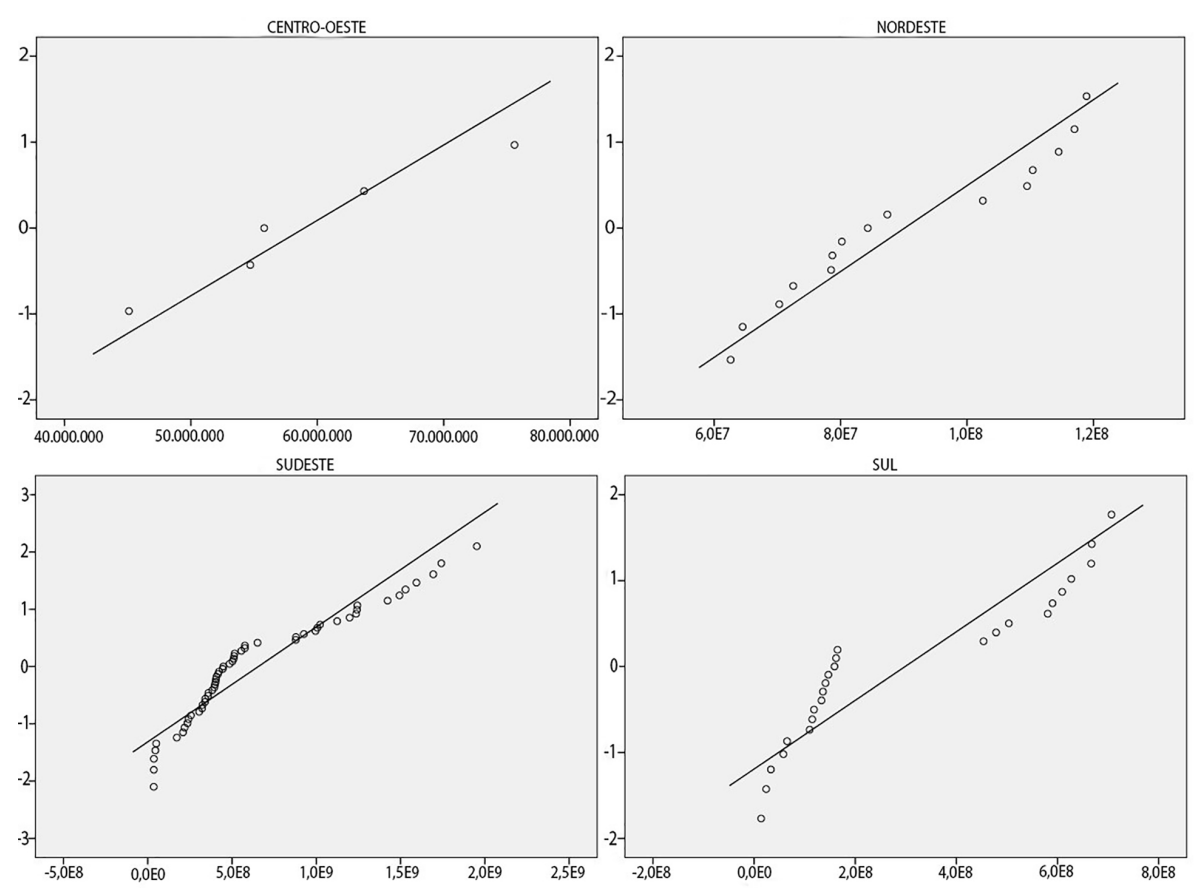

FIGURA 1

Tendência de normalidade de VM por regióes

Fonte: dados da pesquisa.

Ao visualizar a tabela 4 percebe-se que, considerando um nível de significância de 5\%, todos os testes tiveram suas hipóteses nulas rejeitadas. Destarte, há evidências de diferenças entre as médias das marcas dos clubes no que se refere à região a qual estes estão inseridos. Este resultado difere daquele obtido por Marçal (2018), uma vez que, em tal pesquisa, somente a região Sudeste apresentou diferença quanto ao valor das marcas dos clubes quando comparada às demais. Isso sugere um aparente aumento nas disparidades interregionais do valor das marcas dos clubes de futebol do Brasil. Contudo, a diferença entre os resultados obtidos nesta pesquisa em relação à anterior possa ser derivada das distintas composições amostrais de tais estudos.

TABELA 4

Testes não paramétricos de diferença de médias

\begin{tabular}{|l|c|}
\hline \multicolumn{1}{|c|}{ Teste (subgrupos testados) } & p-valor \\
\hline Kruskal Wallis (Todos) & 0,0000 \\
\hline Mann-Whitney (Centro-Oeste / Nordeste) & 0,0005 \\
\hline Mann-Whitney (Centro-Oeste / Sudeste) & 0,0001 \\
\hline Mann-Whitney (Centro-Oeste / Sul) & 0,0130 \\
\hline Mann-Whitney (Nordeste / Sudeste) & 0,0000 \\
\hline Mann-Whitney (Nordeste / Sul) & 0,0020 \\
\hline Mann-Whitney (Sudeste / Sul) & 0,0030 \\
\hline
\end{tabular}

Fonte: dados da pesquisa.

Conforme descrito na seção de procedimentos metodológicos, em um primeiro momento, a variável VM foi considerada no modelo de regressão em seu valor original. O teste Jarque-Bera, indicado por Gujarati e Porter (2011) como ferramenta eficaz na verificação da normalidade dos resíduos de regressões, reportou um p-valor $<0,0000$. O resultado indica a ausência de normalidade dos resíduos, mas para confirmar esta tendência, foi feita uma análise diante do gráfico exposto na figura 2. 


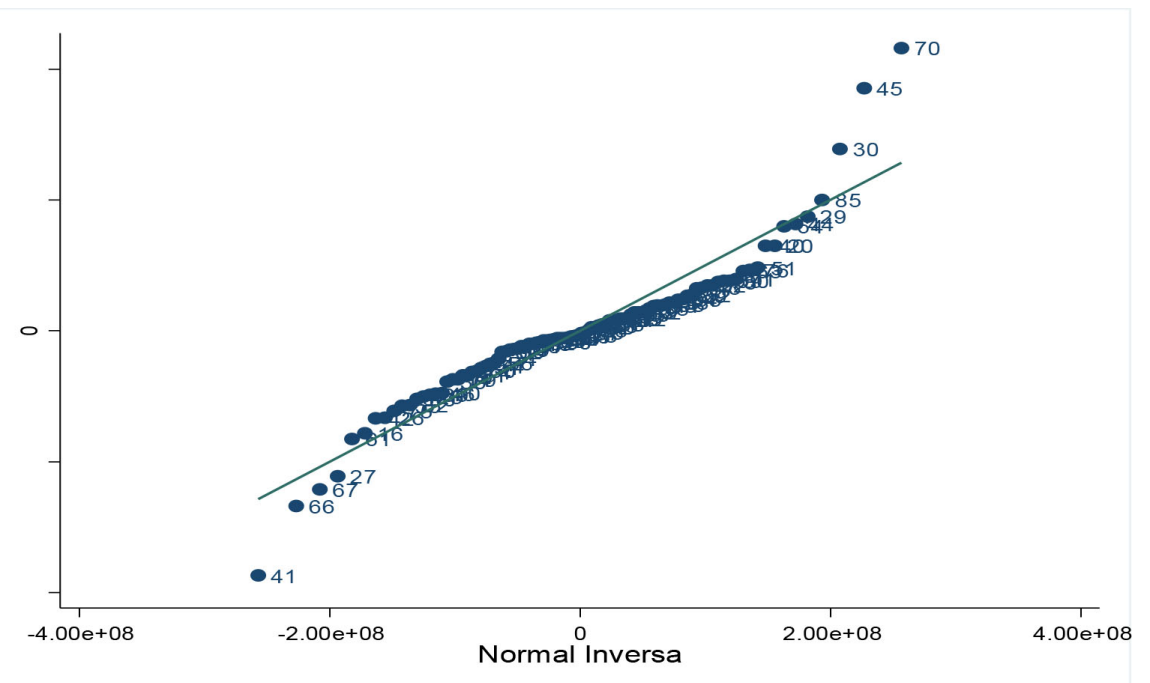

FIGURA 2

Normalidade dos resíduos (VM em valor original)

Fonte: dados da pesquisa.

O teste parece ser válido considerando, também, a análise gráfica. Na sequência, o mesmo gráfico é apresentado, abordando, porém, a variável VM em forma de logaritmo neperiano.

Pela figura 3 é possível identificar uma notável melhoria na tendência de normalidade dos resíduos após a transformação da variável VM. Contudo, duas observações $\left(\mathrm{n}^{\circ} 21\right.$ e $\left.\mathrm{n}^{\circ} 24\right)$ se destacam como potenciais entraves na adequação do modelo. Considerando isso e a repetida rejeição da hipótese nula por meio do teste Jarque-Bera ( $\mathrm{p}$-valor $<0,0000)$, estas duas observações foram excluídas da base de dados.

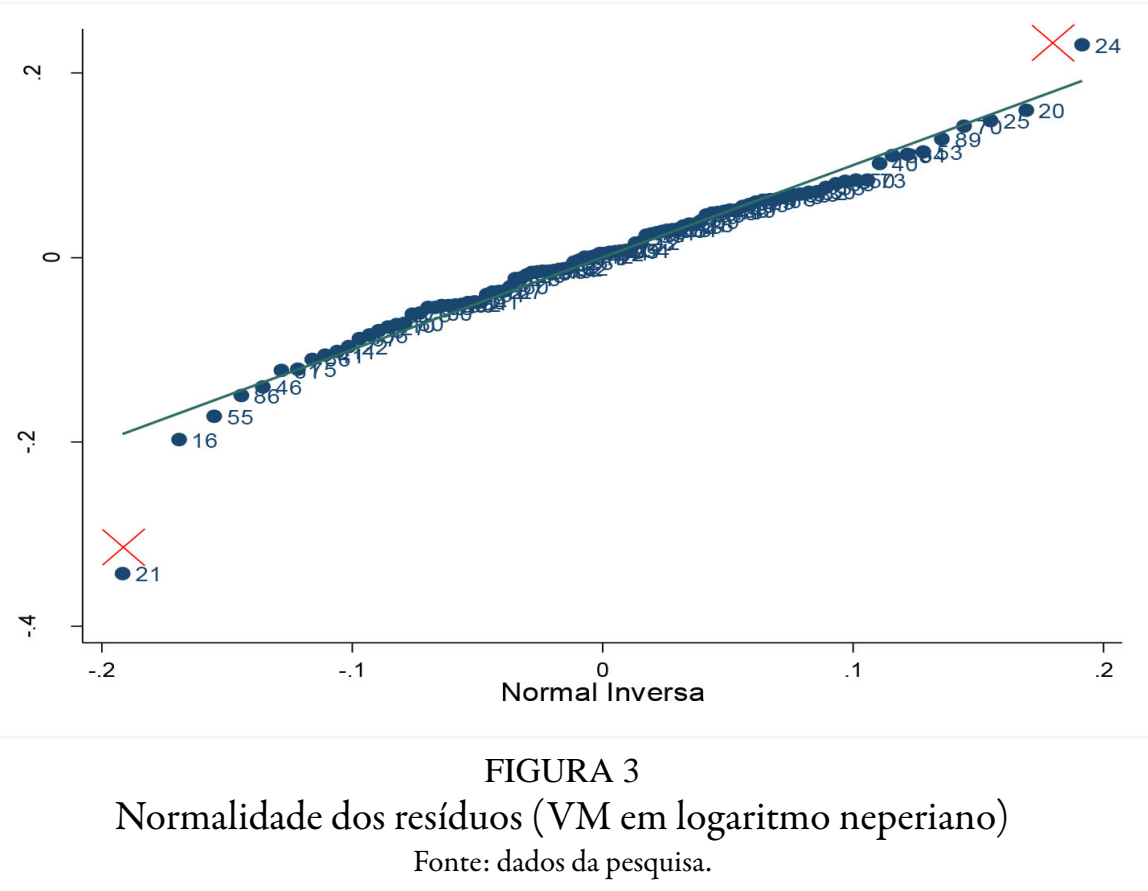

Após tais exclusões, o diagnóstico de normalidade via teste Jarque-Bera apontou um p-valor de 0,7408 , ou seja, foi aceita a hipótese nula de que os resíduos apresentam comportamento aparentemente normal. Isso foi corroborado diante das figuras 4 e 5. 


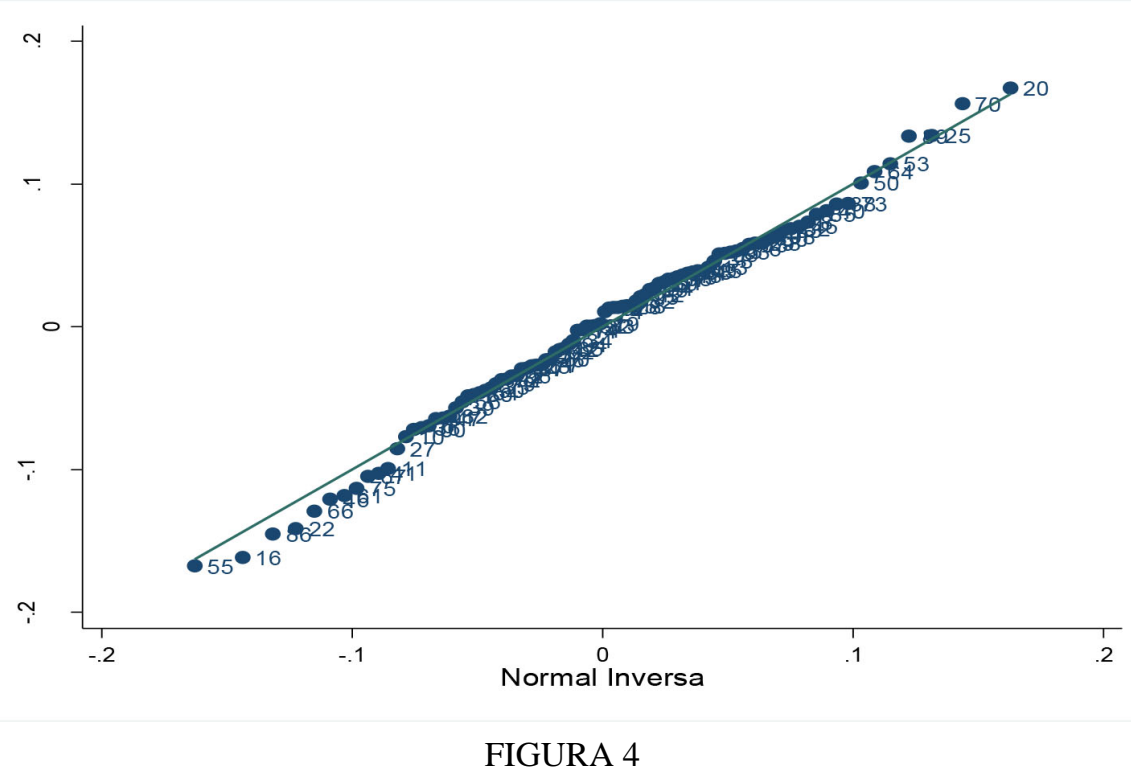

Normalidade dos resíduos (VM em logaritmo neperiano; 2 observações excluídas) Fonte: dados da pesquisa.

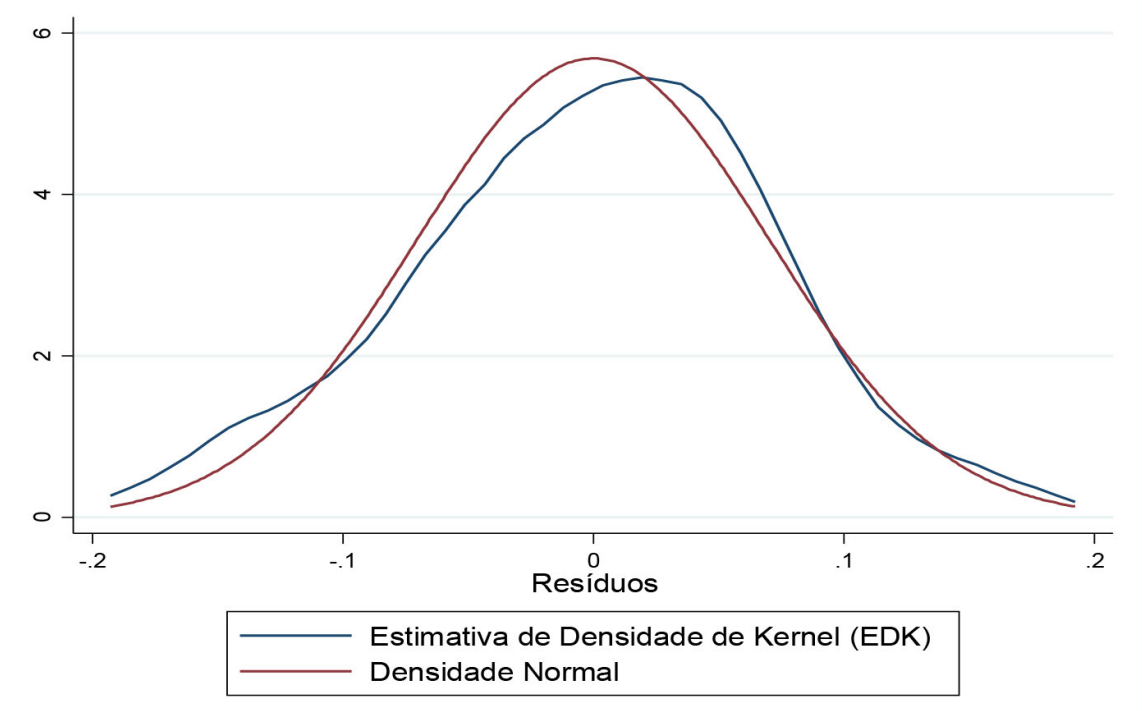

FIGURA 5

Estimativa de Densidade de Kernel x Densidade Normal Fonte: dados da pesquisa.

Em seguida, foi realizado o teste da Razão de Verossimilhança para a verificação da homocedasticidade dos resíduos, seguindo a sugestão de Baltagi, Jung e Song (2010) de que tal teste é o mais adequado para dados em painel com abordagem de efeitos aleatórios. O teste apontou um p-valor de 0,0000 sugerindo heterocedasticia entre os resíduos. Isso foi confirmado diante do gráfico disposto na figura 6. 


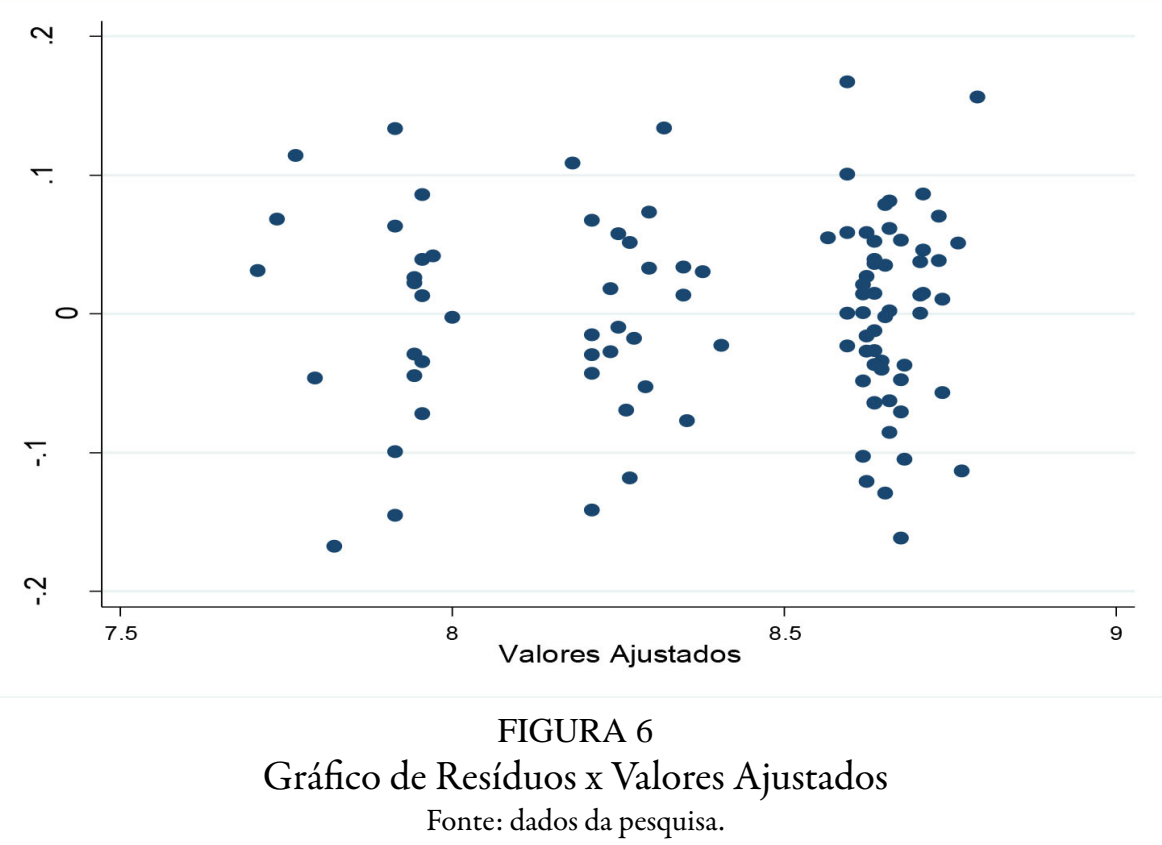

Nota-se diante da figura 6 que há uma alta variância inicialmente, mas ao passo que os valores ajustados aumentam, esta variância tende a diminuir. Em função da aparente heterocedasticidade foi utilizada a correção de White como medida corretiva. Tal correção decorre da adequação dos erros-padrão, tornando-os robustos (Gujarati \& Porter, 2011).

Finalmente, no que diz respeito a multicolinearidade, não há indícios de graves problemas dado que nenhum regressor apresentou Fator de Inflação da Variância (FIV) superior a 10 unidades (Gujarati \& Porter, 2011). Como forma de análise complementar desse aspecto é apresentada a matriz de correlação dos dados na tabela 5.

TABELA 5

Matriz de correlação

\begin{tabular}{|l|l|l|l|l|l|l|l|}
\hline & \multicolumn{1}{|c|}{$\operatorname{lnVM}$} & \multicolumn{1}{|c|}{ NORD } & \multicolumn{1}{|c}{ SUD } & SUL & LIBERT & PERM & ROD \\
\hline $\operatorname{lnVM}$ & 1,000 & & & & & & \\
\hline NORD & $-0,4214^{* * *}$ & 1,000 & & & & & \\
\hline SUD & $0,5363^{* * *}$ & $-0,4808^{* * *}$ & 1,000 & & & & \\
\hline SUL & $-0,1061$ & $-0,2354^{* *}$ & $-0,6263^{* * *}$ & 1,000 & & & \\
\hline LIBERT & $0,4471^{* * *}$ & $-0,2892^{* * *}$ & $0,2477^{* *}$ & 0,0375 & 1,000 & & \\
\hline PERM & $-0,0985$ & $-0,2234^{* *}$ & $-0,0886$ & 0,0500 & 0,1178 & 1,000 & \\
\hline ROD & 0,0120 & 0,1109 & 0,0815 & $-0,1248$ & $-0,0504$ & $-0,5855^{* * *}$ & 1,000 \\
\hline
\end{tabular}

Nota: * nível de confiança de $90 \%$; ** nível de confiança de $95 \%$; *** nível de confiança de $99 \%$.

Fonte: dados da pesquisa.

Dentre os regressores, a correlação de maior intensidade é aquela entre as variáveis binárias SUD e SUL $(-0,6263)$. Este resultado também indica que não há colinearidade problemáticas entre as variáveis de estímulo ao considerar o limite de 0.9 disposto por Green, Tull e Albaum (1988). Diagnosticadas as condições necessárias para as devidas inferências por meio da equação previamente descrita, tem-se a análise de regressão na tabela 6 . A tabela 6 indica que o modelo proposto, de uma forma geral, é estatisticamente signi Æcativo a um nível de conÆança de $99 \%$, vide p-valor $(\mathrm{F})<0,01$. Ademais, percebe-se um poder de explicação geral $\left(\mathrm{R}^{2}\right)$ capaz de explanar aproximadamente $37 \%$ da variação da variável de resposta. 
TABELA 6

Análise de regressão do modelo proposto

\begin{tabular}{|l|l|c|c|c|}
\hline \multicolumn{5}{|c|}{ Painel A } \\
\hline InVM & \multicolumn{1}{|c|}{ Coeficiente } & Erro-padrão & $t$ & $p$-valor \\
\hline NORD & $0,322^{* * *}$ & 0,071 & 4,52 & 0,000 \\
\hline SUD & $1,003^{* * *}$ & 0,166 & 6,04 & 0,000 \\
\hline SUL & $0,618^{* * *}$ & 0,200 & 3,09 & 0,002 \\
\hline LIBERT & 0,024 & 0,026 & 0,91 & 0,365 \\
\hline PERM & $0,029^{* *}$ & 0,012 & 2,38 & 0,017 \\
\hline ROD & $0,069^{* * *}$ & 0,025 & 2,74 & 0,006 \\
\hline Intercepto & $7,535^{* * *}$ & 0,096 & 78,14 & 0,000 \\
\hline \multicolumn{5}{|c|}{ Painel B } \\
\hline R ${ }^{2}$ Geral & \multicolumn{5}{|c|}{0,374} & $N^{\circ}$ de observações & 98 \\
\hline Qui-quadrado & 87,643 & F $>\chi 2$ & 0,000 \\
\hline
\end{tabular}

Nota: * nível de confiança de $90 \%$; ** nível de confiança de $95 \%$; *** nível de confiança de $99 \%$.

Fonte: dados da pesquisa.

Todas as variáveis de controle que se referem às regiões demográficas foram significativas e apresentaram sinal positivo, sendo o destaque a par da variável SUD, que apresenta o maior coeficiente entre todos regressores. Este resultado sugere que os clubes da região Sudeste são melhor avaliados pelo mercado, tal qual havia reportado a pesquisa de Marçal (2018).

Diferentemente do esperado, a variável LIBERT é insignificante em termos estatísticos (p-valor 0,365). Embora a participação na Copa Libertadores traga benefícios financeiros para os clubes (Dantas et al., 2016), ela não é capaz de influenciar o valor das marcas dos clubes. Quanto às variáveis de interesse, nota-se que ambas (PERM e ROD) são estatisticamente significativas dado um nível de significância de $5 \%$, haja vista seus respectivos p-valores 0,017 e 0,006 .

O sinal positivo de PERM indica que, no âmbito do futebol, há benefícios na manutenção de longo prazo na relação com as firmas de auditoria, uma vez que tal manutenção tende a aumentar o valor das marcas dos clubes. Este resultado segue a tendência geral de pesquisas correlatas, conforme Manry et al. (2008), e contraria à lógica reportada por Junaidi et al. (2014) de que haveria redução de independência dos auditores em longos relacionamentos, prejudicando a qualidade da auditoria e, consequentemente, da qualidade das informações contábeis divulgadas. Com tal resultado, não é fiável rejeitar a $\mathrm{H} 1$ da presente pesquisa. A variável ROD, de igual forma, apresenta um sinal positivo responsável pela não rejeição da H2. Há evidências perante a amostra selecionada de que o rodízio das firmas de auditoria é saudável para os clubes de futebol, alavancando o valor de suas marcas. Isso indica que, no futebol, o conhecimento específi co adquirido pelos auditores durante longos períodos de trabalho (embora seja importante) não é algo essencial a ponto de prejudicar a qualidade da auditoria, contrariando Beck e Wu (2006).

Defond e Subramanyam (1998) e Silvestre et al. (2018) haviam reportado ganhos em termos de qualidade informacional nas demonstrações contábeis no momento da troca das firmas de auditoria. Isso parece ocorrer também com os clubes de futebol, pois uma informação de melhor qualidade agregaria mais valor de mercado em função da confiança obtida pelos sócios no processo de avaliação dos clubes (Moreira et al., 2013).

Em suma, é possível considerar diante dos resultados da pesquisa que o relacionamento entre o clube auditado e a firma de auditoria não deve ser de curto prazo. Porém, a troca da firma também é desejável, sendo, inclusive, mais impactante no valor das marcas dos clubes, dado que o coeficiente de ROD foi 0,069 e coeficiente de PERM foi 0,029. Este resultado deve ser considerado com limitaçóes, visto que não é possível saber se a troca contínua de firmas seria um fator constantemente positivo, bem como não é possível saber se os benefícios da permanência da Ærma assumem um comportamento linear ascendente constante.

Percebe-se que a qualidade da auditoria -aqui representada pelo tempo de permanência e pelo rodízio das firmas- surge como importante característica na determinação de valor dos clubes de futebol por meio 
da confiabilidade gerada nas demonstrações contábeis por eles reportadas, inclusive, quando tais clubes são caracterizados como entidades sem fins lucrativos (Silva \& Carvalho, 2009). Isto ratifica-se, considerando as deficientes gestões nos clubes de futebol (Oliveira et al., 2017), e o fato de que a auditoria é um dos elementos capazes de reduzir a assimetria informacional e o problema de agência no futebol (Rezende \& Dalmácio, 2015).

\section{Conclusões}

O futebol é o esporte mais popular do país e, diante dessa popularidade, os clubes brasileiros usufruem de uma relação de fidelidade contínua por parte de seus torcedores, que são os consumidores finais de todas as ações deste esporte.

Além disso, diversos estudos, a nível nacional e internacional, foram realizados recentemente tendo em vista a grande quantia de recursos financeiros envolvida no funcionamento do futebol profissional.

Por serem, em geral, entidades sem fins lucrativos, os clubes de futebol do Brasil não possuem um valor de mercado exato, a exemplo de cotações de ações em empresas de capital aberto. Todavia, diante da medida de valor das marcas desses clubes - métrica desenvolvida pela BDO RCS Auditores Independentes- este estudo buscou analisar a influência da qualidade da auditoria no valor das marcas dos clubes brasileiros de futebol.

Isso foi feito considerando as benesses derivadas de uma auditoria de qualidade perante as informações contábeis. Como as gestões dos clubes de futebol do Brasil são marcadas por atos de ineficiência e até mesmo fraudes, segundo alguns autores, tem-se a possibilidade de maior relevância da auditoria ao exercer seu papel de fiscalização.

Em face de 98 observações válidas concernentes a 20 diferentes clubes entre 2014 e 2018, foi possível verificar que o tempo de permanência da firma de auditoria em um determinado clube é um fator significativo positivo em relação ao valor da marca deste clube. De igual forma, o rodízio das firmas de auditoria também denota vantagens nesse sentido. Com isso, as hipóteses $\mathrm{H} 1$ e $\mathrm{H} 2$ da presente pesquisa não puderam ser rejeitadas.

Os resultados são amparados por pesquisas correlatas anteriores e sustentam a ideia de que, nos clubes de futebol, o relacionamento de longo prazo entre uma firma de auditoria e um dado clube é bem visto pelo mercado, não havendo, aparentemente, desconfianças diante de uma possível perda de independência do auditor. Isso está de acordo com a maioria de pesquisas sobre o tema.

Porém, por ser o rodízio das firmas uma condição igualmente positiva (reportando, inclusive, maior magnitude em seu coeficiente, comparado ao assunto anterior), implica-se que, embora o mercado valide relacionamentos longos com uma firma de auditoria, quando os clubes optam por serviços de uma nova firma, há também uma validação aparente do mercado. Ou seja, não são esperados relacionamentos de curto prazo, mas em um dado momento, é salutar realizar o rodízio.

Este trabalho contribui teoricamente ao acrescentar resultados em um campo escasso de pesquisas, qual seja, da auditoria independente no âmbito do futebol. Igualmente, o estudo contribui de forma prática ao fornecer um diagnóstico sobre a influência da qualidade da auditoria no valor das marcas dos clubes, algo passível de grande interesse para sócios, torcedores, dirigentes, auditores, dentre outras partes interessadas.

Tem-se, ainda, uma contribuição de caráter social ao explanar para os fanáticos torcedores de futebol do Brasil uma possível influência da qualidade da auditoria no valor das marcas de seus clubes.

Assim como em qualquer pesquisa, os resultados aqui percebidos devem ser compreendidos com certas limitações, a saber:

I) não é cabível qualquer generalização de inferências, uma vez que o estudo contempla apenas uma parte dos clubes de futebol do Brasil, em um determinado intervalo de tempo; II) como visto, para a amostra selecionada na pesquisa, não foi identificada sequer uma auditoria de grande porte (Big four). Como essa 
é uma característica recorrentemente utilizada em pesquisas sobre a qualidade da auditoria, os resultados deste estudo estão restritos; e III) os desfechos quanto ao rodízio das firmas de auditoria e seu tempo de permanência em um certo clube não podem ser vistos como de efeitos contínuos, ou seja, talvez rodízios constantes não sejam benéficos, bem como a permanência da firma por um período muito longo pode vir a ser mal considerada pelo mercado.

Como sugestões para pesquisas futuras, indica-se, portanto: a) o estudo da escolha dos clubes por uma determinada firma de auditoria, visando perceber os determinantes capazes de causar a nuance da nãopresença de firmas Big four no cenário futebolístico; b) a análise, em distintos períodos, de quando o tempo de permanência da firma de auditoria é significativo ou não na determinação do valor da marca de um clube; e c) a utilização de amostras compostas por clubes de diversas nações na aspiração de comparações que poderiam (ou não) identificar especificidades da auditoria em clubes de futebol realizada no Brasil.

\section{Considerações éticas}

Cabe destacar que a pesquisa não exigiu endosso ético por parte dos autores, tendo em vista que se trata de uma contribuição derivada de dados públicos de caráter primário ou secundário.

\section{Contribuição dos autores}

Ronan Reis Marçal: esboço do problema de pesquisa, articulação teórica, proposta metodológica, desenvolvimento das hipóteses de pesquisa, análise dos resultados e especificação das considerações gerais do artigo. Luiz Alberton: articulação teórica, especificação das considerações gerais do artigo e revisão geral.

\section{Conflitos de interesse}

Não há conflitos de interesse dos autores em quaisquer aspectos da pesquisa.

\section{Agradecimentos}

O trabalho não foi financiado por qualquer instituição específica.

\section{Referências}

Al-Thuneibat, A. A., Al Isa, R. T. I., \& Ata Baker, R. A. (2011). Do audit tenure and firm size contribute to audit quality? Managerial AuditingJournal, 26(4), https://doi.org/10.1108/02686901111124648

Baltagi, B. H., Jung, B. C., \& Song, S. H. (2010). Testing for heteroskedasticity and serial correlation in a random effects panel data model.Journal of Econometrics, 154(2), 122-124. https://doi.org/10.1016/j.jeconom.2009.04.009

BDO. (2018). $11^{\circ}$ Valor das Marcas dos Clubes Brasileiros. Recuperado de https://www.bdo.com.br/pt-br/publicaco es/noticias-em-destaque/11\%C2\%BA-valor-das-marcas-dos-clubes-brasileiros

Beck, P. J., \& Wu, M. G. (2006). Learning by doing and audit quality. Contemporary Accounting Research, 23(1), 1-30. https://doi.org/10.1506/AXU4-Q7Q9-3YAB-4QE0

Becker, C. L., DeFond, M. L., Jiambalvo, J., \& Subramanyam, K. R. (1998). The effect of audit quality on earnings management. Contemporary Accounting Research, 15(1), 1-24. https://doi.org/10.1111/j.1911-3846.1998.tb0 0547.x 
Carey, P., \& Simnett, R. (2006). Audit partner tenure and audit quality. The Accounting Review, 81(3), 653-676. htt ps://doi.org/10.2308/accr.2006.81.3.653

Cox, R. A., \& Weirich, T. R. (2002). The stock market reaction to fraudulent financial reporting. Managerial Auditing Journal, 17(7), 374-382. https://doi.org/10.1108/02686900210437471

Dantas, J. A., \& Medeiros, O. R. (2015). Determinantes de qualidade da auditoria independente em bancos. Revista Contabilidade \& Finanças-USP, 26(67), 43-56. https://doi.org/10.1590/1808-057x201400030

Dantas, M. G. S., \& Boente, D. R. (2011). A eficiência financeira e esportiva dos maiores clubes de futebol europeus utilizando a análise envoltória de dados. Revista de Contabilidade e Organizações, 5(13), 75-90. https://www.re dalyc.org/pdf/2352/235222080006.pdf

DeAngelo, L. E. (1981). Auditor size and audit quality. Journal of Accounting and Economics, 3(3), 183-199. https:/ /doi.org/10.1016/0165-4101(81)90002-1

Decreto-Lei n. 3.199, de 14 de abril de 1941. (1941). Estabelece as bases de organização dos desportos em todo o país. Diário Oficial da União, Rio de Janeiro.

DeFond, M. L., \& Subramanyam, K. R. (1998). Auditor changes and discretionary accruals. Journal of accounting and Economics, 25(1), 35-67. https://doi.org/10.1016/S0165-4101(98)00018-4

DeFond, M., \& Zhang, J. (2014). A review of archival auditing research. Journal of Accounting and Economics, 58(2-3), 275-326. https://doi.org/10.1016/j.jacceco.2014.09.002

Deis Jr, D. R., \& Giroux, G. A. (1992). Determinants of audit quality in the public sector. The Accounting Review, 67(3), 462-479. https:// https://www.jstor.org/stable/247972?seq=1

Fávero, L. P., \& Belfiore, P. (2017). Manual de análise de dados: estatística e modelagem multivariada com Excel ${ }^{\circ}$, SPSS ${ }^{\circ}$

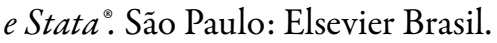

Figueiredo, G. H., Santos, V., \& Cunha, P. R. (2017). Práticas de evidenciação em entidades desportivas: Um estudo nos clubes de futebol brasileiros. Enfoque: Reflexão Contábil, 36(1), 1-21. https://doi.org/10.4025/enfoque.v3 6i1.28467

Galindo, C. H. A. (2016). Os direitos dos atletas em formação e a Lei 6.354/76: consequências das transferências entre clubes. Revista Cientifica Intraciência, (11), 1-26. https:// http://uniesp.edu.br/sites/_biblioteca/revistas/2017 0531134006.pdf

Ghosh, A., \& Moon, D. (2005). Auditor Tenure and Perceptions of Audit Quality. The Accounting Review, 80, 585-612. https://doi.org/10.2308/accr.2005.80.2.585

Green, P. E., Tull D. S., \& Albaum, G. (1988). Research for Marketing Decisions. Englewood Cliffs: Prentice Hall.

Gujarati, D. N., \& Porter, D. C. (2011). Basic econometrics. Boston, Mass: McGraw-Hill. DOI ou URL

Holanda, A. P., Meneses, A. F. D., Mapurunga, P. V. R., De Luca, M. M. M., \& Coelho, A. C. D. (2012). Determinantes do nível de disclosure em clubes brasileiros de futebol. Revista de Contabilidade do Mestrado em Ciências Contábeis da UERJ, 17(1), 2-17. http://www.atena.org.br/revista/ojs-2.2.3-06/index.php/UERJ/article/view Article/1291

Jensen, M. C., \& Meckling, W. H. (1976). Theory of the firm: Managerial behavior, agency costs and ownership structure. Journal of Financial Economics, 3(4), 305-360. https://doi.org/10.1016/0304-405X(76)90026-X

Junaidi, J., Apriyanto, H. P., Nurdiono, N., \& Suwardi, E. (2014). The effect of audit firm tenure in artificial rotation on audit quality. Journal of Economics, Business \& Accountancy Ventura, 17(3), 439-448. http://dx.doi.org/10. 14414/jebav.v17i3.365

Kaveski, I. D., \& Cunha, P. D. (2016). Fatores determinantes dos honorários da auditoria das empresas listadas no Novo Mercado da BM\&FBOVESPA. Contabilidade, Gestão e Governança, 19(1), 49-63. https://www.revistacgg.org /contabil/article/view/846

Khani, M. K., \& Noroozian, M. (2018). Analyzing the Effective Factors on Internal Audit Quality of Health Insurance Organization of Iran. International Journal of Academic Research in Accounting, Finance and Management Sciences, 8(1), 19-25. https://ideas.repec.org/a/hur/ijaraf/v8y2018ilp19-25.html 
Lawrence, A., Minutti-Meza, M., \& Zhang, P. (2011). Can Big 4 versus non-Big 4 differences in audit-quality proxies be attributed to client characteristics? The Accounting Review, 86(1), 259-286. https://doi.org/10.2308/accr.0 0000009

Lei n. 10.672, de 15 de maio de 2003. (2003). Altera dispositivos da Lei no 9.615, de 24 de março de 1998, e dá outras providências. Diário Oficial da União, Brasília.

Lei n. 9.615, de 24 de março de 1998. (1998). Institui normas gerais sobre desporto e dá outras providências. Diário Oficial da União, Brasília.

Lopes, H. D., \& Davis, M. D. (2007). O ativo jogador de futebol. Pensar Contábil, 8(33). 1-10. http://www.atena.or g.br/revista/ojs-2.2.3-06/index.php/pensarcontabil/article/view/23

Manry, D. L., Mock, T. J., \& Turner, J. L. (2008). Does increased audit partner tenure reduce audit quality? Journal of Accounting, Auditing \& Finance, 23(4), 553-572. https://doi.org/10.1177/0148558X0802300406

Marçal, R. R. (2018). Contabilidade Desportiva: Um estudo sobre o impacto dos investimentos na formação de atletas nas marcas dos clubes brasileiros de futebol. Revista Mineira de Contabilidade, 19(2), 68-76. https://doi.org/1 $0.21714 / 2446-9114 \mathrm{RMC} 2018 \mathrm{v} 19 \mathrm{n} 2 \mathrm{t} 06$

Mattar, M. (2014). Na trave: o que falta para ofutebol brasileiro ter uma gestão profissional. Rio de Janeiro: Elsevier Brasil.

Moreira, F., Firmino, J., Silva, R., \& Silva, J. (2013). Qualidade da auditoria nos clubes de futebol brasileiro: Abordagem sobre o julgamento dos auditores independentes na redução ao valor recuperável de ativos. Apresentado no XXXVII EnANPAD, Rio de Janeiro, RJ, Brasil. Recuperado de http://www.anpad.org.br/ anpad/eventos.php?cod_eve nto $=1 \&$ cod_edicao_subsecao $=9668$ cod_evento_edicao $=68 \&$ cod_edicao_trabalho $=15842$

Myers, J. N., Myers, L. A., \& Omer, T. C. (2003). Exploring the term of the auditor-client relationship and the quality of earnings: A case for mandatory auditor rotation? The Accounting Review, 78(3), 779-799. https://doi.org/1 0.2308/accr.2003.78.3.779

Oliveira, M. C., Borba, J. A., Ferreira, D. D. M., \& Lunkes, R. J. (2017). Características da estrutura organizacional dos clubes de futebol brasileiros: o que dizem os estatutos? Revista de Contabilidade e Organizações, 11(31), 47-57. https://www.revistas.usp.br/rco/article/view/134462

Razali, N. M., \& Wah, Y. B. (2011). Power comparisons of shapiro-wilk, kolmogorov-smirnov, lilliefors and anderson-darling tests. Journal of Statistical Modeling and Analytics, 2(1), 21-33. https://www.researchgate.net/profile/Bee-Yap/publication/267205556_Power_Comparisons_of_Sha piro-Wilk_Kolmogorov-Smirnov_Lilliefors_and_Anderson-Darling_Tests/links/5477245b0cf29afed61446e 1/Power-Comparisons-of-Shapiro-Wilk-Kolmogorov-Smirnov-Lilliefors-and-Anderson-Darling-Tests.pdf

Rezende, A.J., \& Dalmácio, F.Z. (2015). Práticas de Governança Corporativa e Indicadores de Performance dos Clubes de Futebol: uma Análise das Relações Estruturais. Revista Contabilidade, Gestão e Governança, 18(3), 105-125. https://revistacgg.org/contabil/article/view/878

Silva, J. A. F., \& Carvalho, F. A. A. (2009). Evidenciação e desempenho em organizações desportivas: um estudo empírico sobre clubes de futebol. Revista de Contabilidade e Organizações, 3(6), 96-116. https://www.redalyc.o rg/pdf/2352/235216393006.pdf

Silva, R. C., Moreira, F. S., Firmino, J. E., Miranda, J. P., \& Silva, J. D. G. (2016). Julgamento dos Auditores Independentes sobre o Ativo Intangível: Um Estudo sobre a Qualidade da Auditoria em Clubes de Futebol do Brasil. Revista Contabilidade e Controladoria, 8(3). 65-81. https://revistas.ufpr.br/rcc/article/view/39449

Silva, T. B. J., Santos, C. A., \& Cunha, P. R. (2017). Relação entre o desempenho econômico-financeiro e o relatório de auditoria dos clubes de futebol brasileiros. Revista de Gestão, Finanças e Contabilidade, 7(3), 177-200. http://www.spell.org.br/documentos/ver/46571/relacao-entre-o-desempenho-economico-financeir o-e-o-relatorio-de-auditoria-dos-clubes-de-futebol-brasileiros/i/pt-br

Silvestre, A. O., Costa, C. M., \& Kronbauer, C. A. (2018). Rodízio de Auditoria e a Qualidade dos Lucros: Uma Análise a Partir dos Accruals Discricionários. Brazilian Business Review, 15(5), 410-426. https://doi.org/10.15728/bb r.2018.15.5.1

Teoh, S. H., \& Wong, T. J. (1993). Perceived auditor quality and the earnings response coefficient. Accounting Review, 68(2) 346-366. https://www.jstor.org/stable/248405?seq=1 
Ronan Reis Marçal, et ai. Qualidade da auditoria no futebol e seus reflexos no valor das ...

Umbelino, W. L., Silva, R. B., Ponte, V. M. R., \& Lima, M. C. (2019). Disclosure em Clubes de Futebol: Estudo sobre os Reflexos da Lei do PROFUT. Revista Evidenciação Contábil \& Finanças, 7(1), 112-132. https://dialnet.uni rioja.es/servlet/articulo?codigo $=6794206$

\section{Notas}

* $\quad$ Artigo de pesquisa científica e tecnológica.

Licencia Creative Commons CC BY 4.0

Para citar este artigo: Marçal, R. R., \& Alberton, L. (2021). Qualidade da auditoria no futebol e seus reflexos no valor das marcas dos clubes brasileiros. Cuadernos de Contabilidad, 22. https://doi.org/10.11144/Javer iana.cc22.qafr 